\title{
Thermal and Structural Analysis of A Ceramic Coated Fsae Brake Rotor Using 3d Finite Element Method for Wear Resistance and Design Optimisation
}

\author{
Promit Choudhury ${ }^{1}$, Rahul Kumar Singh ${ }^{2}$, Pritish Panda ${ }^{3}$ \\ ${ }^{1}$ (Mechanical, SRM University, India) \\ ${ }^{2}$ (Mechanical, SRM University, India) \\ ${ }^{3}$ (Automobile, SRM University, India)
}

\begin{abstract}
This paper describes the stress distribution of the SRM University FSAE Car brake rotor by using FEA. The finite element analysis is performed by using computer aided design (CAD) software. The main objective is to investigate and analyze the thermal and structural stress distribution of brake rotor at the real time condition during braking process and then comparing it with a modified rotor having ceramic coating. The paper describes the mesh optimization with using finite element analysis technique to predict the higher stress and critical region on the component. The optimization is carried out to reduce the stress concentration and material on the surface of the rotor. With using computer aided design (CAD), SOLIDWORKS software the structural model of a brake rotor is developed. Furthermore, the finite element analysis performed with using software ANSYS.
\end{abstract}

Keywords: Magnesium Zirconate, Nickel-Chromium Aluminium, Optimization, Stainless Steel 420, Thermal Resistance.

\section{INTRODUCTION}

The parametric optimization of existing brake discs is an integral part of the brake system design procedure as many of the parameters defining the brake's geometry and performance are often dictated by packaging constraints (the wheel diameter and offset influence the rotor diameter and caliper size respectively). Therefore, it is imperative to look for the highest performance within the system constraints.

With any design problem there are objectives and constraints that must be met. With mechanical design, size, weight, strength, and cost are a few of the many constraints that may need to be taken into consideration when designing for a set of objectives. With finite element analysis and optimization, more complex problems can be solved more quickly, decreasing the amount of physical testing for a new design. An optimum design can be achieved based on predetermined criteria using computational methods.

Sometimes unforeseen problems arise and additional design goals need to be met; it is also possible to determine where and how changes should be made, if the intended use of the new product were to change, because all conditions for optimization are known. This helps address the cases where non-optimal designs may continue to be used to cut the time, cost, and risk of trying to find a better design. For these reasons, finite element techniques were chosen as the design method for designing a disc brake rotor.

The optimization of automotive vehicles braking systems, subjected to mechanical and thermal stresses, depends on a combination of properties. In general, a complex state of stress is found and it is practically impossible to select a material and design a component based only on one of these properties. The material used in brake rotors should be able to bear thermal fatigue and should absorb and dissipate, as soon as possible, the heat generated during braking. The high thermal conductivity allowing lower temperatures in the region under friction, which contributes to an increase in life of the component. Mechanical and thermal properties of stainless steel may be improved through the addition of ceramic coatings on the surface which in contact with the brake pad.

Finite element optimization techniques are used to design a single alloy disc brake rotor that is lighter and performs as well as existing single alloy rotors. The scope of this paper is to investigate rotor design using topological optimization for a single alloy disc brake rotor. All finite element analysis and optimization is done on a linear finite element solver. Under normal braking, the rotor should remain in its elastic region. Otherwise the rotor would deform after each use.

\section{DESIGN METHODOLOGY}

To develop the optimized product commonly by reducing the weight while ensuring that it meets the design functionality and reliability. Structural optimization tools like topology and shape optimization along with manufacturing simulation are becoming attractive tools in product design process. These tools also help to 
reduce product development time. Objective of this investigation is to reduce weight and wear of brake rotor system. This paper focuses on thermal and static analysis. Finite element analysis has been used to implement optimization and maintaining stress and deformation levels and achieving high stiffness. Reduction of weight has been one the critical aspects of any design along with reduction in deformation and stress factors, which increases the life of the product. It has a substantial impact on vehicle performance.

Validation process is an important step in this design optimization. The optimized model's performance is compared with initial models.

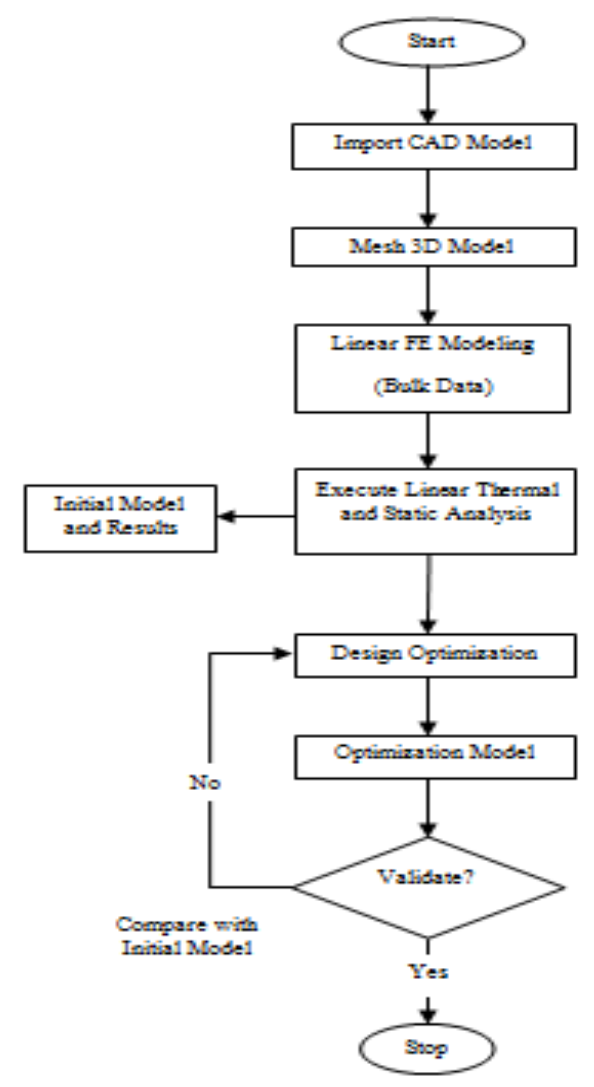

Fig1. Design optimization flowchart

III.

MATERIAL SELECTION

The primary base material selected for the rotor is stainless steel due to its strength, hardness and corrosion resistance. Other materials like Cast iron and aluminum were also considered as alternatives initially but cast iron becomes too brittle if used in low thickness rotors and though aluminum dissipates more heat but it needs to be anodized with hard coat to withstand the deformations. Finally Hardened 420 stainless steel is chosen for its high strength to weight ratio and tensile strength, its availability in the local market also plays a prominent role.

The zirconia-based ceramic coatings are used as thermal barrier coatings owing to their low conductivity and their relatively high coefficients of thermal expansion, which reduce the detrimental interfacial stresses.

Table1. MATERIAL SPECIFICATION

\begin{tabular}{|l|l|l|l|l|l|l|l|}
\hline Serial Number & Material & $\begin{array}{l}\text { Thermal } \\
\text { Conductivity } \\
\left(\mathrm{W} / \mathrm{m}^{\circ} \mathrm{C}\right)\end{array}$ & $\begin{array}{l}\text { Thermal } \\
\text { Expansion } 10^{-6} \\
\left(1 /{ }^{\circ} \mathrm{C}\right)\end{array}$ & Density $\left(\mathrm{Kg} / \mathrm{m}^{3}\right)$ & $\begin{array}{l}\text { Specific Heat } \\
\left(\mathrm{J} / \mathrm{kg}^{\circ} \mathrm{C}\right)\end{array}$ & $\begin{array}{l}\text { Poisson's Ratio } \\
\text { Moung's }\end{array}$ & \begin{tabular}{l} 
Yodulus $(\mathrm{Gpa})$ \\
\hline 1.
\end{tabular} \\
\hline 2. & $\mathrm{SS} 420$ & 18 & 6.8 & 7800 & 460 & 0.3 & 200 \\
\hline 3. & $\mathrm{NiCrAl}$ & 16.1 & 12 & 7870 & 764 & 0.27 & 90 \\
\hline
\end{tabular}

IV. BRAKE SYSTEM SPECIFICATION

Table2. SPECIFICATION DATASHEET

\begin{tabular}{|l|l|}
\hline Assumed weight of the car & $350 \mathrm{Kgs}$ \\
\hline Assumed CG height & $0.31 \mathrm{~m}$ \\
\hline Wheelbase & $1.6 \mathrm{~m}$ \\
\hline Maximum Deceleration rate & $1.5 \mathrm{G}$ \\
\hline
\end{tabular}




\begin{tabular}{|l|l|}
\hline Front/Rear tire radius & $0.255 \mathrm{~m}$ \\
\hline Maximum leg input & $35 \mathrm{kgs}$ \\
\hline pedal ratio & $4: 1$ \\
\hline Front/Rear master cylinder diameter & $0.015875 \mathrm{~m}$ \\
\hline Front/Rear caliper diameter & $0.0445 \mathrm{~m}$ \\
\hline Friction coefficient of pad & 0.46 \\
\hline Front disc diameter & $0.24 \mathrm{~m}$ \\
\hline Rear disc diameter & $0.24 \mathrm{~m}$ \\
\hline Front pad height & $0.08 \mathrm{~m}$ \\
\hline Rear pad height & $0.08 \mathrm{~m}$ \\
\hline
\end{tabular}

V.

MODEL AND Numerical ANALYSIS

V.I. DESIGNING A CAD MODEL

CAD model of brake rotor was developed in 3D modeling software SOLIDWORKS, it consists of bolt holes for mounting, holes on surface for heat dissipation, out periphery is designed such that the stress concentration can be reduced and also for cleaning of pads. Rotor design mainly depends on caliper and the wheel- rim internal diameter.

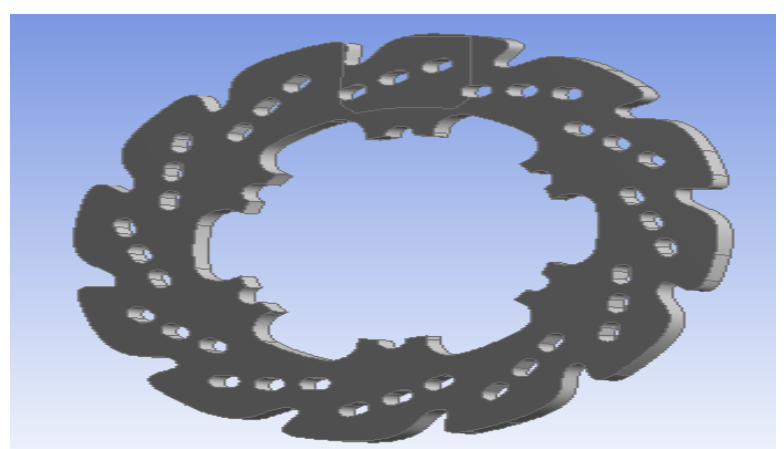

Fig2. Initial model of brake rotor

An initial CAD model of rotor is modeled with a rotor thickness of $7 \mathrm{~mm}$ and rotor diameter of 240 $\mathrm{mm}$. Takqing the initial design as reference, a modified geometry with different layers of ceramic coating has been modeled. The new model has 5 layers where the first layer is of $350 \mu \mathrm{m}$ and the second layer is of $150 \mu \mathrm{m}$ and the third layer is of $6 \mathrm{~mm}$ and again the similar coating layers of similar thickness is followed on the other side of the third layer.

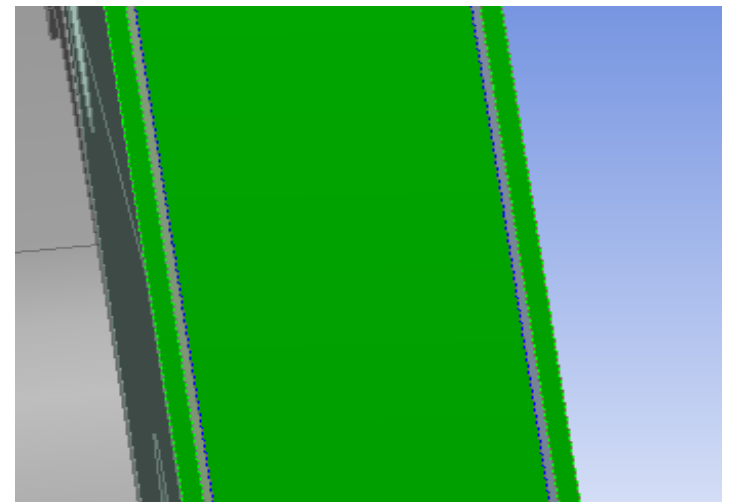

Fig3. Patch showing five different layers

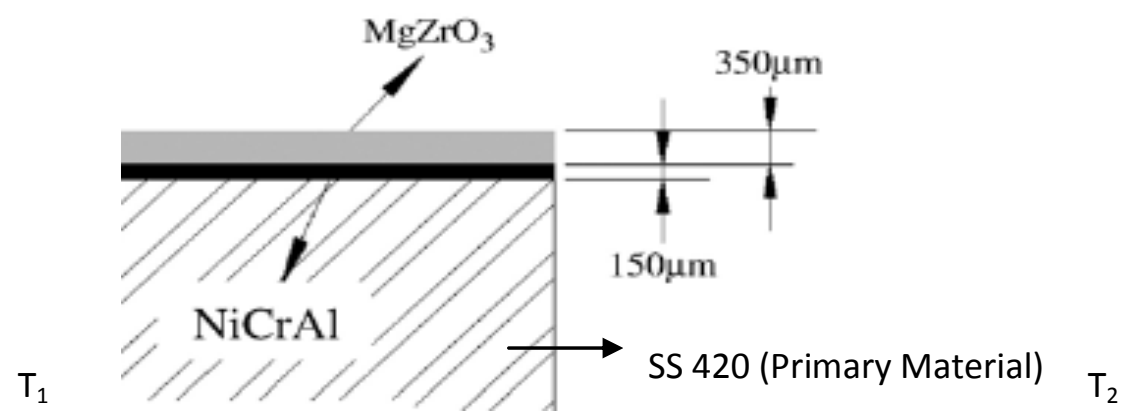

Fig4. Layers of coating on primary material 


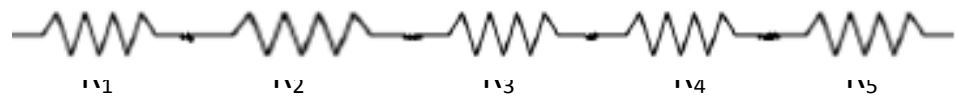

Fig5. Thermal circuit resistance model for heat transfer from the rotor ( $\mathrm{R} 1: \mathrm{MgZrO}_{3}$ resistance, $\mathrm{R} 2$ :

$\mathrm{NiCrAl}$ resistance, R3: SS 420 resistance, $\mathrm{R} 4$ : $\mathrm{NiCrAl}, \mathrm{R} 5: \mathrm{MgZrO}_{3}$ resistance)

\section{V.II. MESHING}

CAD model of rotor converted into Parasolid file. This model is imported into Ansys Workbench simulation. Geometry cleanup was performed prior to meshing of model. Finite element model was developed using Ansys Workbench Simulation. For better quality of mesh fine element size is selected.

\section{V.III. BOUNDARY CONDITION AND FORCE DISTRIBUTION AND ANALYSIS}

The analysis is a coupled type analysis as the thermal analysis is done and the residual thermal stress are imported to the static structural analysis. For thermal analysis, boundary condition, convection heat coefficient is applied along with the heat flow throughout the body, and then it is solved in terms of temperature and heat flux. The thermal stress is imported to static structural analysis. The boundary condition and loading condition were set following conditions for testing purpose in one automotive manufacturing company. The boundary conditions were defined by fixing all the bolt holes surfaces. The force is applied to the patch where the brake pad touches the instant when brake is applied. It is solved in terms of total deformation, equivalent stress and equivalent strain.

\section{V.IV. CALCULATION}

1. Master cylinder area $=3.14 * 0.25 *$ Master cylinder diameter ${ }^{2}$

$=0.0001978323 \mathrm{~m}^{2}$

2. Calliper Area

$=3.14 * 0.25 *$ Piston diameter*Piston diameter

$=0.001551005 \mathrm{~m}^{2}$

3. Effective radius

$=((($ Front disc diameter/2)-front pad height $) / 2)+$ Front pad height

$=(((0.24 / 2)-0.08) / 2)+0.08$

$=0.1 \mathrm{~m}$

4. Weight of the car $=350 * 9.812$

$=3433.50 \mathrm{~N}$

5. Static front weight $=0.4 *$ weight of the car

$$
=1373.40 \mathrm{~N}
$$

6. Static Rear weight $=(3433.50-1373.40) \mathrm{N}$

$$
=2060.10 \mathrm{~N}
$$

7. Dynamic weight Transfer $=($ Max Deceleration*Centre of Gravity Height*weight $) /$ wheelbase*9.812

$$
\begin{aligned}
& =1.5 * 9.812 * 0.310 * 3433.50 /(1.6 * 9.812) \\
& =997.86 \mathrm{~N}
\end{aligned}
$$

8. Dynamic Front weight $=$ Static front weight + Dynamic weight transfer

$$
\begin{aligned}
& =1373.40 \mathrm{~N}+997.86 \mathrm{~N} \\
& =2371.26 \mathrm{~N}
\end{aligned}
$$

9. Dynamic Rear weight $=$ Static rear weight + Dynamic weight transfer

$$
\begin{aligned}
& =2060.10 \mathrm{~N}+997.86 \mathrm{~N} \\
& =1062.24 \mathrm{~N}
\end{aligned}
$$

10. Required torque $=$ Weight of car*Tire radius*Maximum deceleration

$$
\begin{aligned}
& =3433.5 * 0.255^{*} 1.5 \\
& =1313.41 \mathrm{Nm}
\end{aligned}
$$

11. Required torque/wheel $=0.7 *$ required torque $/ 2$ 


$$
=459.69 \mathrm{Nm}
$$

12. Net leg output $=$ Leg input force*pedal ratio

$$
\begin{aligned}
& =350 * 4 \\
& =1400 \mathrm{~N}
\end{aligned}
$$

13. Front Bias force $\quad=0.7 *$ leg output

$$
\begin{aligned}
& =0.7 * 1400 \\
& =980 \mathrm{~N}
\end{aligned}
$$

\#Note: the brake system is front biased by $70 \%$ due to dynamic weight transfer during braking.

14. Line pressure $=$ Front bias force*Master cylinder Area

$$
\begin{aligned}
& =980 * 0.0001978323 \\
& =4953691.44 \mathrm{~Pa}
\end{aligned}
$$

15. Net front torque generated $=$ Front line pressure $*$ Caliper area $*$ Coefficient of friction*Effective radius $* 2 * 2$ $=4953691.44 * 0.001551005 * 0.46 * 0.1 * 4$

$=1413.71 \mathrm{Nm}$

16. Net rear torque generated $=$ Rear line pressure $*$ Caliper area $*$ Coefficient of friction*Effective radius $* 2 * 2$ $=2123010.62 * 0.001551005 * 0.46 * 0.1 * 4$

$=605.87 \mathrm{Nm}$

17. Net torque generated $=$ Net front torque generated + Net rear torque generated

$$
=1413.71+605.87
$$

$$
=2019.58 \mathrm{Nm}
$$

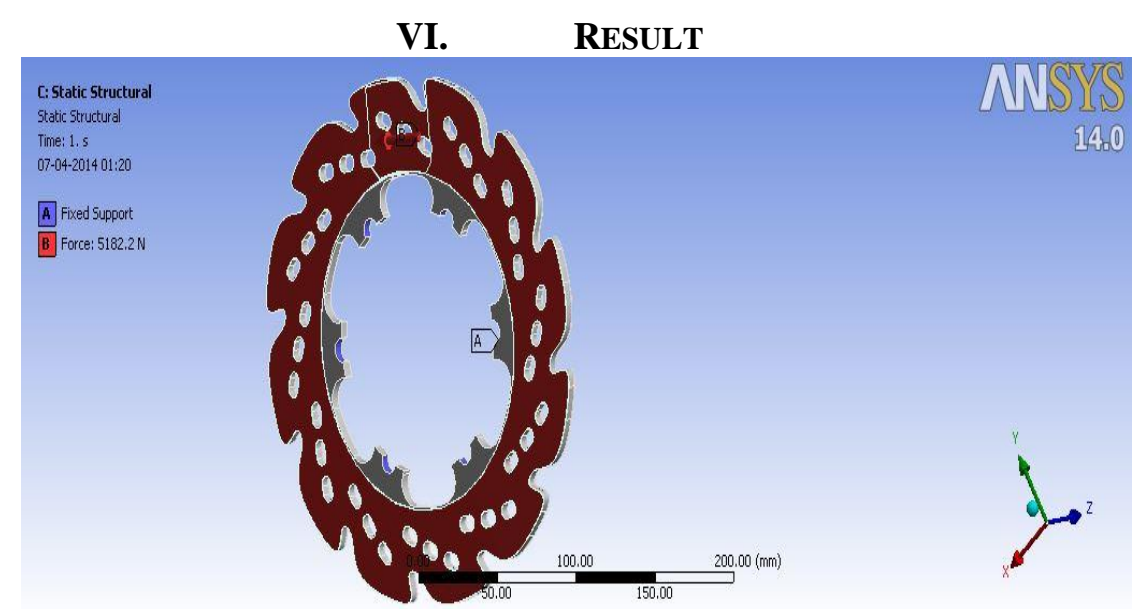

Fig6. Constrains for static analysis

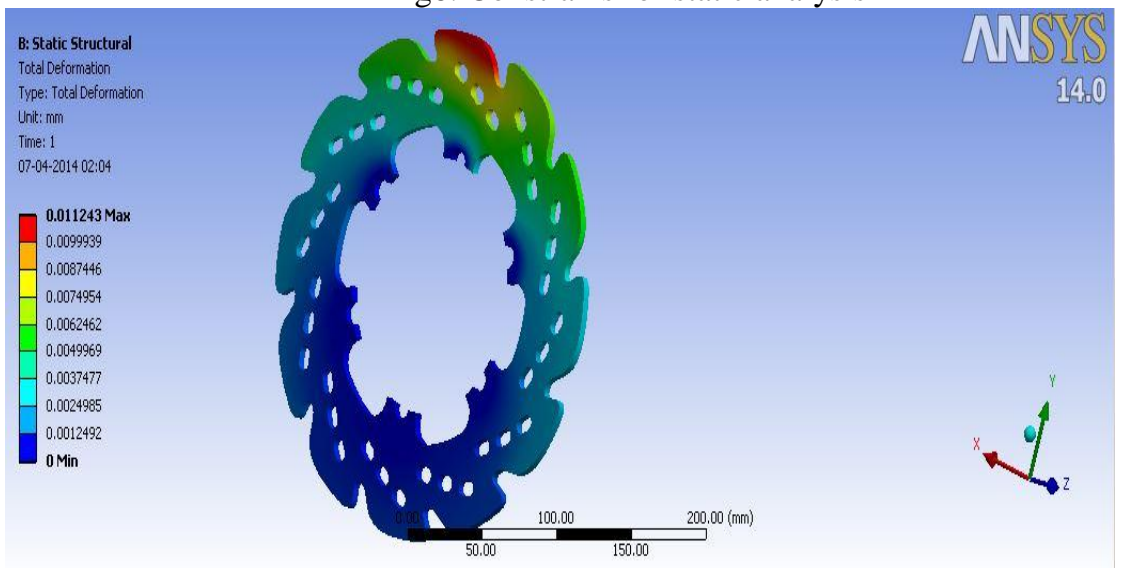

Fig7. Total deformation for the rotor without ceramic coating 


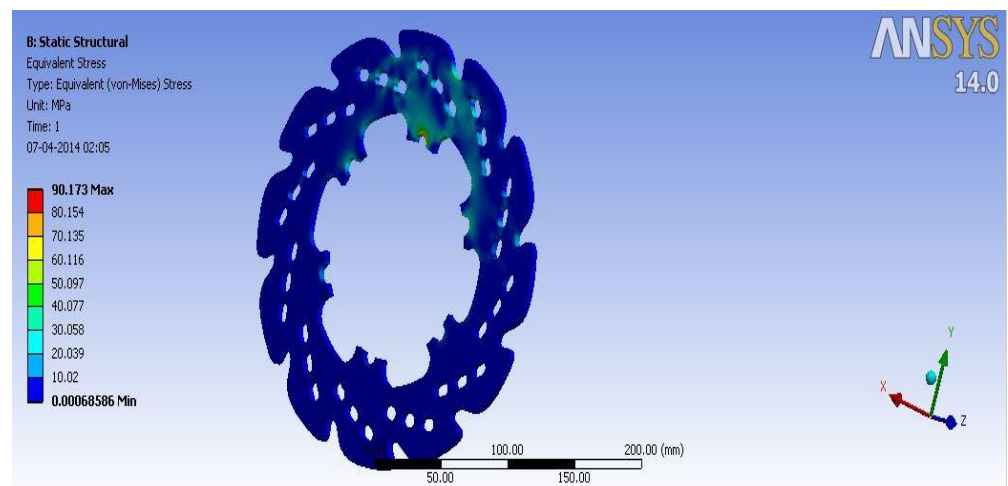

Fig8. Von Mises stress for the rotor without ceramic coating

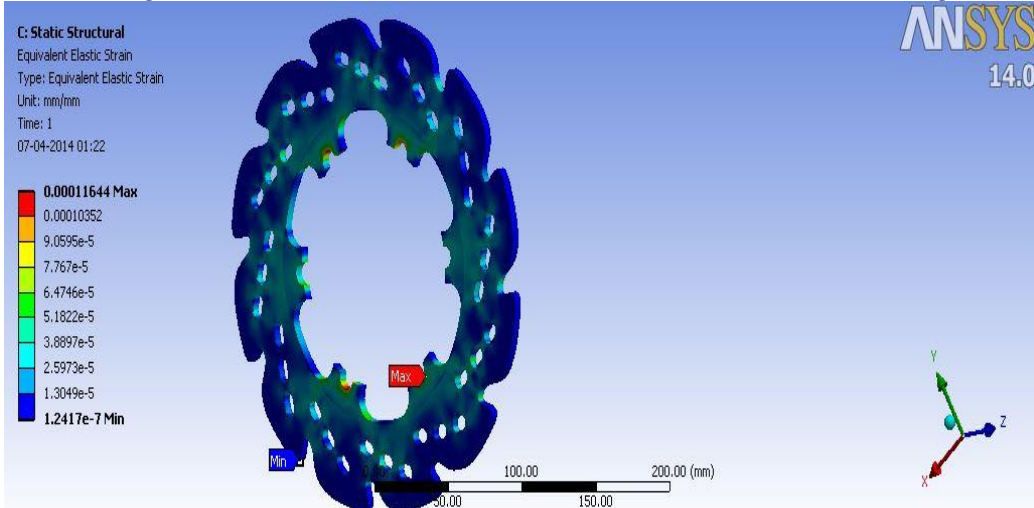

Fig9. Equivalent elastic strain for the rotor without ceramic coating

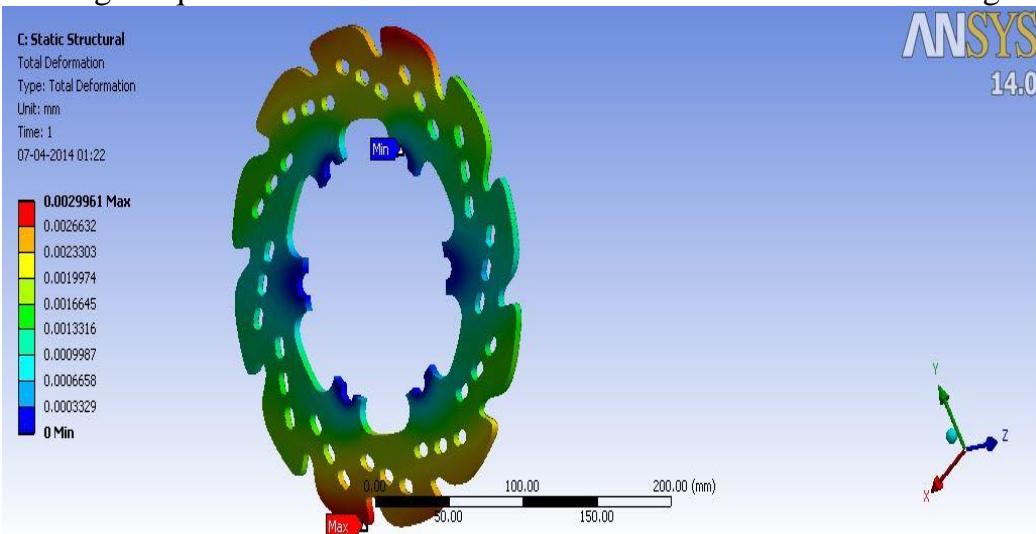

Fig7. Total deformation for the rotor with ceramic coating

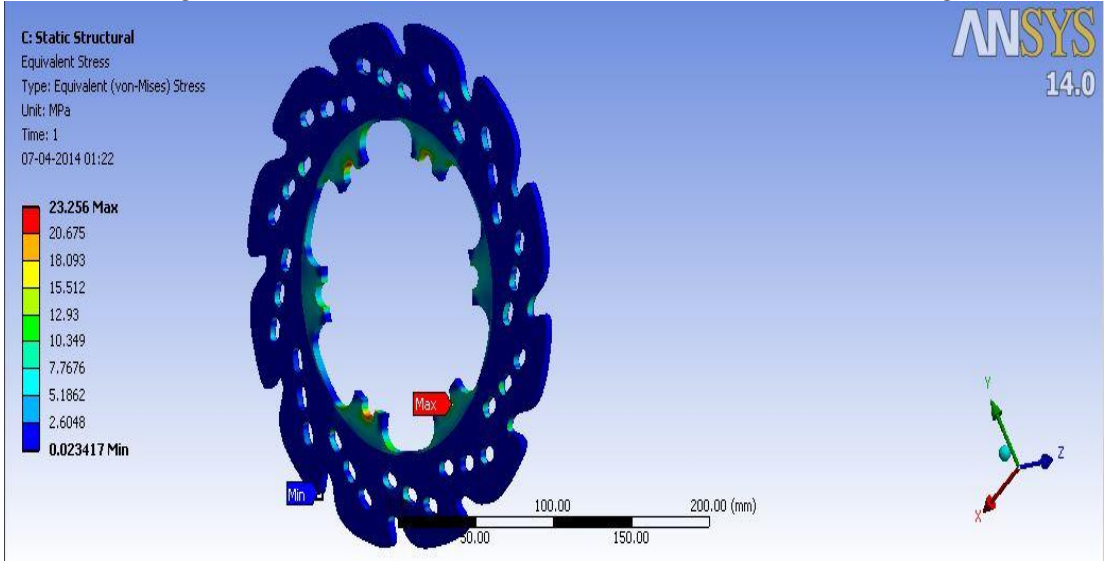

Fig7. Von Mises stress for the rotor with ceramic coating 

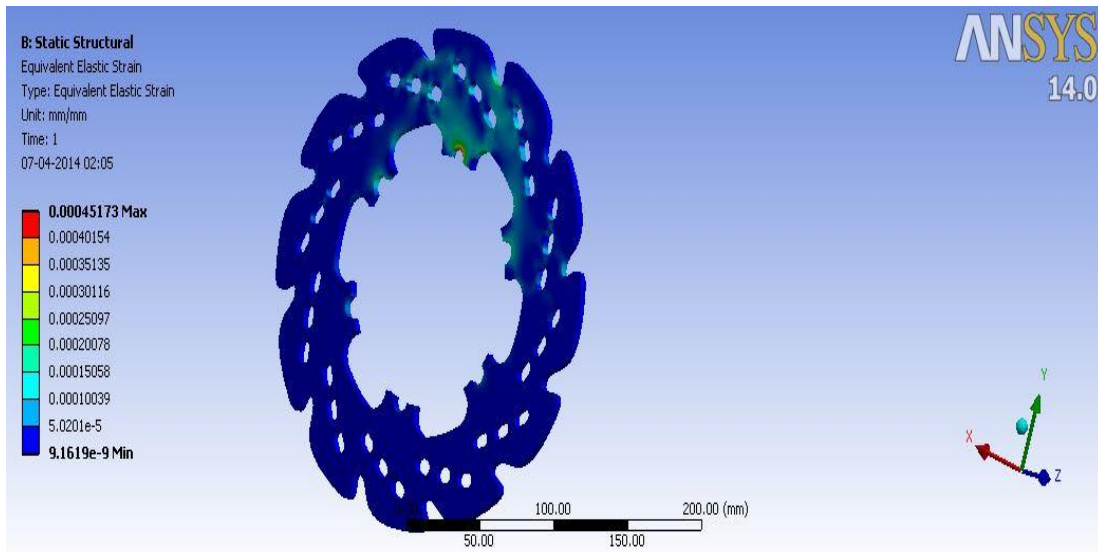

Fig7. Equivalent elastic strain for the rotor with ceramic coating

Table3. POST PROCESSING ANALYSIS RESULT

\begin{tabular}{|c|c|c|c|c|c|}
\hline Serial Number & Material & $\begin{array}{c}\text { Deformation } \\
(\mathrm{mm})\end{array}$ & $\begin{array}{c}\text { Von Mises Stress } \\
(\mathrm{MPa})\end{array}$ & Equivalent Strain & Weight (grams) \\
\hline 1. & $\begin{array}{c}\text { SS420 Rotor (Initial } \\
\text { Design) }\end{array}$ & 0.0112 & 90.173 & 0.0004517 & 1.246 \\
\hline 2. & $\begin{array}{c}\text { SS420 Rotor coated } \\
\text { with ceramic } \\
(\text { NiCrAl-MgZrO } \\
\text { Optimized Design) }\end{array}$ & 0.0029 & 23.256 & 0.0001164 & 1.1202 \\
\hline
\end{tabular}

\section{VII.}

\section{CONCLUSION}

Optimization method used in this study in reducing the mass of brake rotor. Validation is done through finite element solver with the initial model and checked that maximum stress and displacement are within control. This optimization process also gives small change on the displacement and stress. The displacement and stress has significantly reduced in the new optimized design proving to provide better life of the product. Therefore, the overall weight of the rotor can be reduced by $10.11 \%$, deformation by $74.11 \%$ and stress by $74.21 \%$.

\section{REFERENCES}

[1]. B. Breuer, K. H. Bill, Brake Technology Handbook (Warrendale, PA: SAE International, 1st English ed., 2008).

[2]. Anderson A., Friction and wear of automotive brakes (Metals Handbook: Friction, Lubrication and Wear Technology, vol. 18, 1992, pp. 569-577)

[3]. P. Dufrenoy, D. Weichert, A thermomechanical model for the analysis of disc brake fracture mechanisms, Journal of Thermal Stresses, 26(8), 2003, 815-828.

[4]. $\quad$ S. Koetniyom. Thermal Stress Analysis of Automotive Disc Brakes, PhD thesis, University of Leeds, Leeds, 2000.

[5]. P. Kinney, Cleanup: Improving Quadrilateral Finite Element Meshes, Technical Report., Ford Motor Company, Dearborn, MI, Feb 2008.

[6] Carlos H., Galindo L., Tirovic, M., Air flow and heat dissipation analysis of commercial vehicle brake discs, Proceedings Automobile for the future, EAEC 11th European Automotive Congress, Budapest, Hungary, 30 May-1 June 2007, paper CV06-3 European Automobile Engineers Cooperation, Vienna. 